\title{
Monitoring of the Water Eutrophycation Process in Red Lake, from Harghita County, Romania
}

\author{
Alina Agafiței, Vasile Lucian Pavel \\ Department of Hydroameliorations and Environmental Protection, Faculty of Hydrotechnics, Geodesy and Environmental Engineering, \\ Technical University “Gh. Asachi” of Yassy, Yassy, Romania \\ Email address: \\ alinaagafitei@yahoo.com (A. Agafiței),pvlpavel@yahoo.com (V. L. Pavel) \\ ${ }^{*}$ Corresponding author \\ To cite this article: \\ Alina Agafiței, Vasile Lucian Pavel. Monitoring of the Water Eutrophycation Process in Red Lake, from Harghita County, Romania. Earth \\ Sciences. Vol. 10, No. 1, 2021, pp. 1-6. doi: 10.11648/j.earth.20211001.11
}

Received: December 5, 2020; Accepted: December 31, 2020; Published: January 15, 2021

\begin{abstract}
The main problem of freshwater lakes in the world, eutrophycation represents the over-enrichment of water by nutrients (nitrogen, phosphorus) and has emerged as one of the leading causes of surface water quality impairment. It is a rapidly growing environmental crisis, and worldwide, the number of coastal areas impacted by eutrophycation phenomenon stands at over 500. This important pollution process sets off a chain reaction in the ecosystem, starting with an overabundance of algae and other aquatic plants, excess which eventually decompose, producing large amounts of carbon dioxide. This paper is the result of researches located in Romania, performed over a period of eight years (2012-2019), in the area of a representative natural dam lake of the country - Red Lake, from Harghita County. Our researches aimed the quality parameters of the Red Lake water, the eutrophication process indicators, and their over time evolution. In order to predict the evolution of the studied pollution phenomenon in time, we used the software package "Surface-water Modeling System SMS 13.0" - the complete surface water solution, which was approached for the first time by Aquaveo. This software provides a comprehensive graphical environment for numerical modeling of eutrophycation, and tools for site characterization, model conceptualization and graphical visualization.
\end{abstract}

Keywords: Eutrophycation, Nutrients, Surface Water Pollution, Modeling, Monitoring

\section{Introduction}

The process of degradation of the environmental factors across the globe has seen a steady ascendant course over past decades, an increasingly worrying trend, with the amount of pollutants, reaching figures that go beyond the imagination and continue to grow in almost geometric progression.

A general threat to all surface waters, not spectacular, but more dangerous through consequences than acute pollution, is the progressive, often latent, almost unnoticed pollution, which accumulates the effect of small sources with diffuse pollution, and takes chronic forms $[1,2]$.

Such a pollution type is the eutrophycation process, our subject of research, characteristic especially for artificial lakes, but also present in the natural ones, which brings particular problems from the water treatment technologies point of view.

The problem of eutrophycation begins where people live, continue with people indifference, and ends with damage to resources we all use and enjoy, so it should matter to everyone.

Protecting water resources starts with sound agricultural and waste management practices. Water pollution in lakes starts when nutrients get into their water, feed algae, which grows and blocks sunlight; in consequence, plants die, and, eventually, algae die too $[1,3,5]$.

Long living and slow growing flora species, which cannot resist competition, although important for biodiversity, generally develop in oligotrophic or mesotrophic waters.

The eutrophycation process is related in Figure 1. 


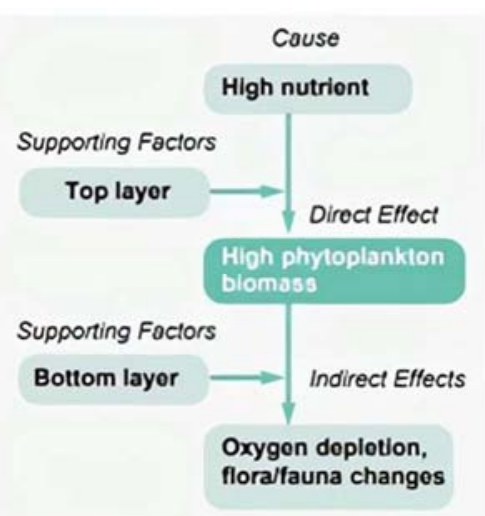

Figure 1. The process of eutrophication.

As a growing and constant preoccupation for the scientific community around the world, the process of eutrophycation is caused both by natural conditions (tide associated accumulation of organic matter, sedimentation areas), and anthropogenic influence (point sources and diffuse sources) (Fugure 2).

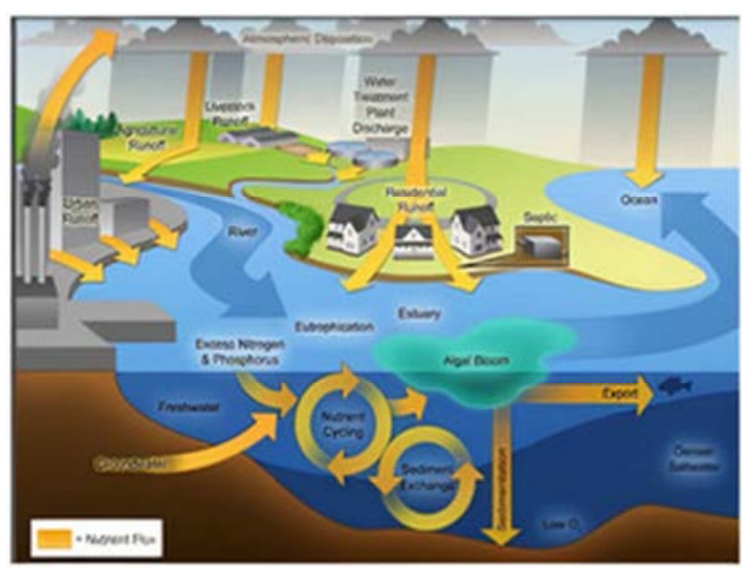

Figure 2. Sources of the eutrophycation process.

\section{Lake Characteristics}

\subsection{Hydro-chemical Parameters}

Red Lake, also named Ghilcoș or Killer Lake - the largest natural dam lake in Romania - is located in the central part of the Eastern Carpathians, in the Hăghima ș Mountains (Hășmașu Mare), on the Bicaz Valley, from Harghita County (Figure 3).

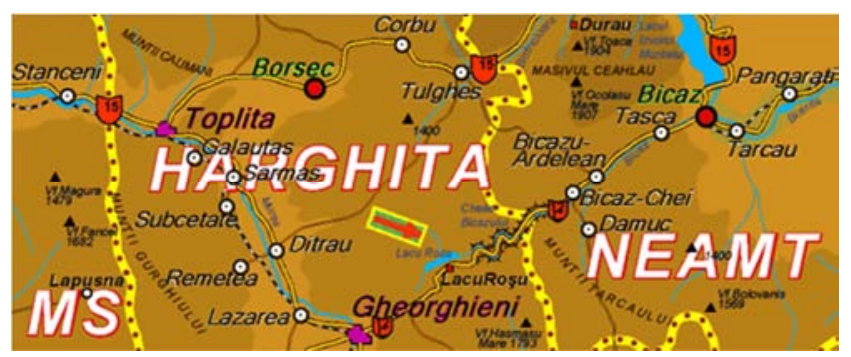

Figure 3. Framing of the studied Lake in the area.

Located at the source of large Carpathian rivers (Olt,
Mureș, Trotuș, and Bicaz), Hăghimaș Mountains constitutes a true oro-hydrographic node of the Carpathians Eastern (Figure 4).

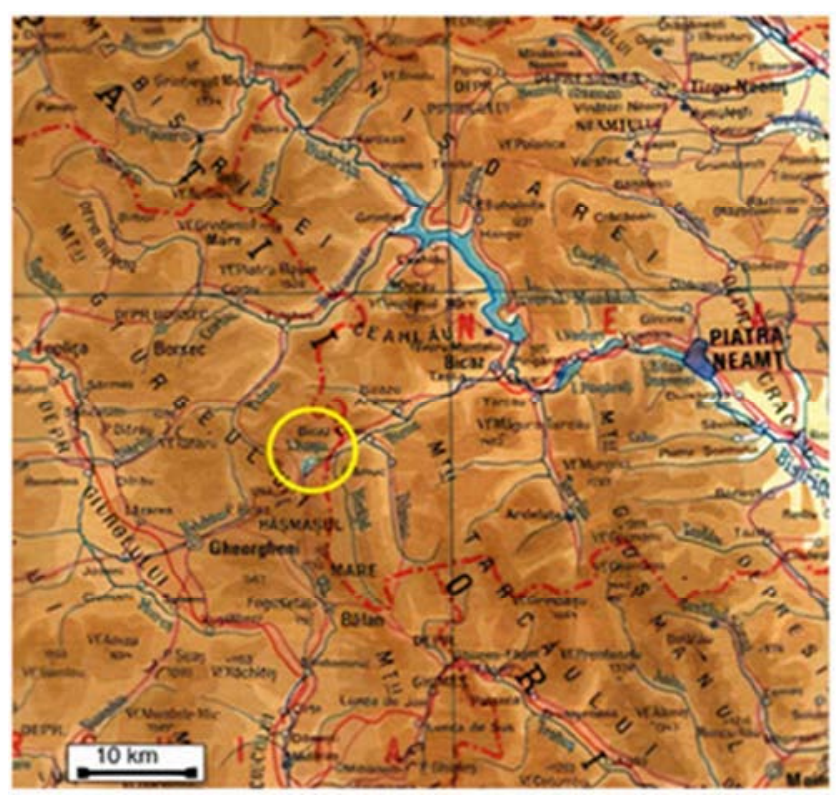

Figure 4. Location of Red Lake on Romania's map (Hăghima Mountains).

Formed in 1837, following a large landslide that affected the mass of deluvial deposits at the base of Ghilcoș Mountain, barring the Bicaz Valley in the confluence sector with Suhard stream, Red Lake is unique in the landscape area from all points of view.

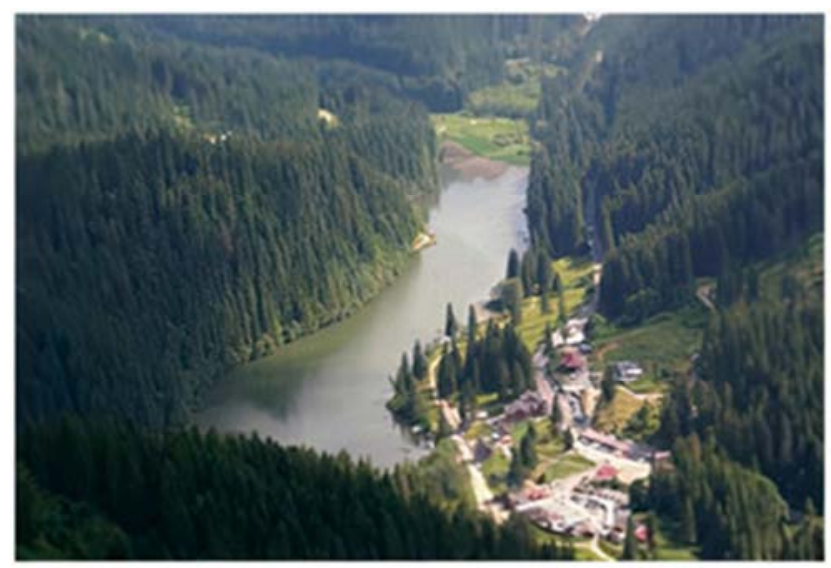

Figure 5. Red Lake - a true recreation paradise.

The lake is arranged approximately in the North - South direction, and has the shape of the letter " $\mathrm{"} \mathrm{returned.} \mathrm{The} \mathrm{short}$ arm is arranged on the West - East and it calls Suhard, the Sheep's Arm is longer, being located on North - South direction.

The main parameters of Red Lake are: the length of the large axis on the Sheep's Arm of $1000 \mathrm{~m}$; the long shaft length on Suhard Valley of $442 \mathrm{~m}$; a total area of 12.6 ha; an average depth of $5.4 \mathrm{~m}$, and maximum depth is about $10.5 \mathrm{~m}$ (highlighted near the mouth of its outflow, in the Bicaz Valley).

At the time of formation, it was estimated that the primary lake surface extended for a length of $2 \mathrm{~km}$ on the Sheep's Arm, 
and $1.6 \mathrm{~km}$ on the Suhard Valley.

After 130 years, studies regarding lake's sedimentation have shown an advance of the clogged area with an average of $2-5 \mathrm{~m} /$ year, the thickness of the sediments reaching between $5-6 \mathrm{~m}$.

Taking into account the volume of sediment accumulated in this period of time, it is estimated that the volume of the Red Lake has decreased by about $40 \%$, in 2016 reaching o. 6 mil. $\mathrm{m}^{3}$.

Physical - chemical parameters were considered as basic criteria in analyzing the habitat changes, also the biotic ones, followed by the algae kenosis structure.

Our preoccupation regarding the hydro-chemical parameters of this lake has considered the principal aspects of the habitat: morph-metric characteristics (depth, length, and width), water mass dynamic, level oscillations, the atmospheric conditions influences, also lake's biotic development $[4,6,7,8,11]$.

The samples were taken in four different sections of the Red Lake, and we used the equipment of a mobile laboratory from Harghita County (Figure 6).

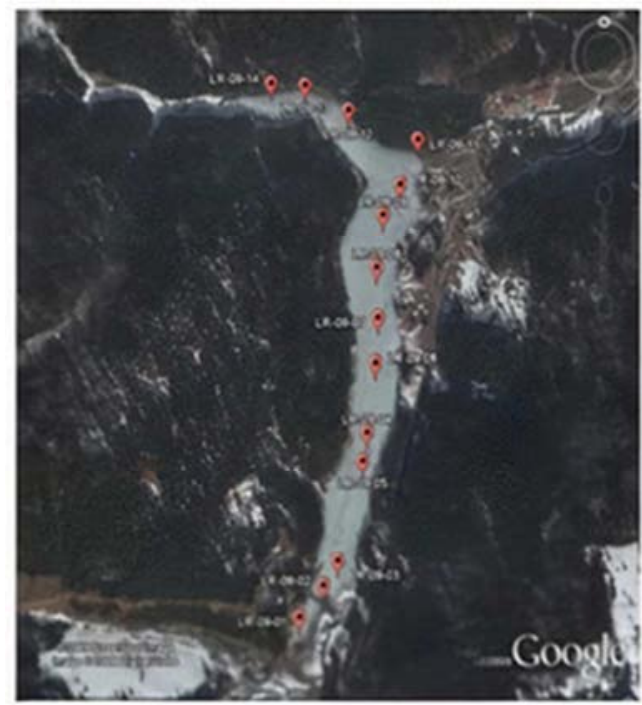

Figure 6. Location of measuring stations of physical - chemical parameters for surface and deep waters of Red Lake, Harghita County.

Analyzes focused on the following important quality indicators for surface waters: dissolved oxygen, nitrates, nitrites, phosphates, $\mathrm{pH}$, organic matter, saturation in $\mathrm{O}_{2}$, and the phytoplankton biomass. Following the determinations made, considering the annual average for each year, the water quality fluctuated between the mesotrophic stage, at the beginning of the research, to the eutrophic lake, towards the end of the period.

\subsection{Trophic Characterization}

From the trophic point of view, we determined and compared the main water parameters, for a period of eight years $\left(2012\right.$ - 2019): $\mathrm{COD} / \mathrm{O}_{2}$ ratio, the phytoplankton biomass, saturation in $\mathrm{O}_{2}, \mathrm{COD}$, and $\mathrm{N}_{\min } / \mathrm{PO}_{4}$ ratio.

We determined the Red Lake water trophic degree using mathematical relations, results that confirmed the land determinations conclusion.

We repeated calculus for every year, using the annual average values of each parameter.

\section{Modeling the Red Lake Water Quality. Surface Modeling System (SMS 13.0)}

Water-quality modeling has evolved appreciably since its innovation in the early years of the twentieth century. There were four periods in the development of water-quality modeling (1925-1960, 1960-1970-computerization, 1970-1977- biology, 1977-present-toxics) [5, 9, 10, 13].

The principal water quality problem addressed since 1970 was the eutrophication process. As a consequence, the environmental modelers broadened their own scope with the purpose of including more mechanistic representations of the biological processes.

Surface Modeling System (SMS 13.0) represents a complete surface water solution, approached as pioneer by Aquaveo.

Building a conceptual model using this software package by constructing a high level representation of the model, using familiar GIS objects (points, arcs, and polygons) - represents a simple, correct and efficient manner of modeling, with a model easily updated or changed as needed.

This environmental software SMS 13.0 is used for hydrodynamic modeling of one-, two-, and three-dimension elaborated in "Environmental Modeling Research Laboratory" (EMRL), at Brigham Young University, with help of the U.S. Army Corps, more exactly with Engineers Waterways Experiment Station (USACE-WES), and U.S. Federal Highway Administration (FHWA) (Figure 7).

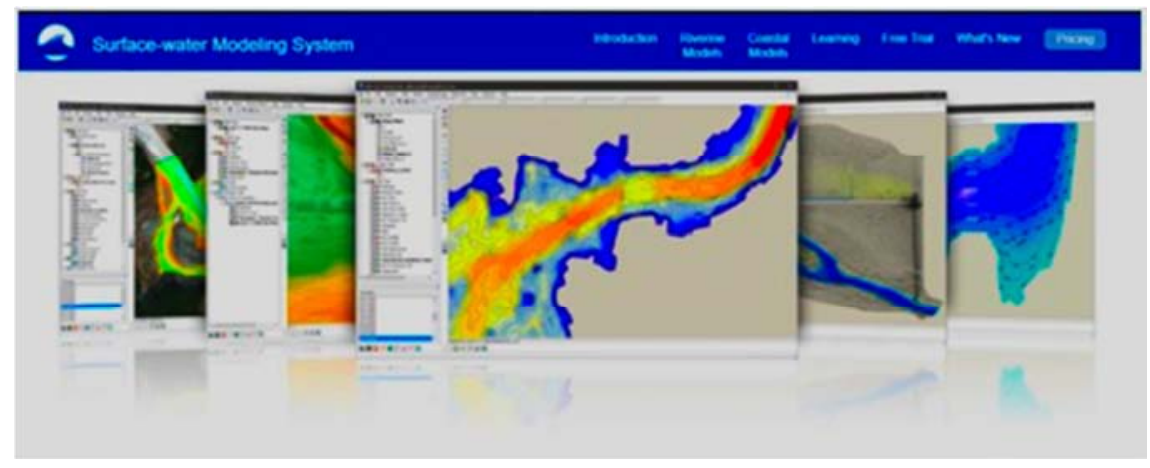

Figure 7. Surface Modeling System - SMS 13.0. 
SMS 13.0 is the most advanced software package available for performing surface water simulations, in a $3 \mathrm{D}$ environment.

Surface Modeling System interface with a wide range of numerical models for applications, including: contaminant transport, riverine analysis, sediment transport, rural flooding, inlet and wave modeling, etc.

Models can cover only a limited number of pollutants. Surface water quality models allow specialists concerned with monitoring the quality of resources to go to the water bodies most permissible for improvements in terms of ecological and chemical view. Many of the knowledge gained over the last decades were based on physical models, but current researches focuses mainly on mathematical models development.

Water quality models are usually classified according to the model complexity, to the type of receiving water, and the water quality parameters (such as: dissolved oxygen, nutrients, etc.) that the model can predict. [3, 5, 10, 13].

These models were studied for a good understanding of their behavior, especially the basic nutrient indicators. For example, the eutrophication parameters concentrations - ammonia, nitrate, and phosphate - can be predicted correctly, with accuracy, at least for simpler water bodies. [2, 11, 12, 14].

For a correct prediction of the algae concentrations, for instance, the procedure is difficult, but commonly done in European Union and Unite States, where the eutrophication phenomenon has become an important concern in the past two decades.

Using SMS 13.0 software, between two sections 1-1 and 2-2 established with lake's data, conform existing norms, at a depth $\mathrm{h}=30 \mathrm{~m}$, for each node (point), the program knows automate the plane coordinates $(\mathrm{x}, \mathrm{y})$ of nodes, in function of three points were we have the coordinates to create the program. Also, nodes were realized in points where we have data for the selected (wanted) field (lake) parameter.

We made the same action for every wanted hydro-chemical indicator.

Using the SMS 13.0 software package, we can establish correlation for points with the same concentration values for any required parameter important for the monitoring of the eutrophycation phenomenon in the considered storage lake. For monitoring and management purposes, the worst possible situation will be high summer temperatures, which exacerbate problems with dissolved oxygen and algal growth, and low flows, which lead to high concentrations of BOD and other pollutants.

Dynamic water quality models need time-series data on flows, temperatures, and other important parameters.

They require both hydraulic data, and base-case concentrations of the water quality parameters of interest (such as: dissolved oxygen, mercury, and so on).

The purpose of these procedures is both to calibrate the models to existing conditions, and to provide a base against which to assess the effects of the monitoring and management alternatives.

The analyzed models also need discharges or loads of the pollutants under consideration from the sources (e.g., the industrial plants) being studied.

Program Interfaces are specifically designed to facilitate the use of numerical models and include the SMS modules. The program consists of the following six modules:

Mesh. It contains tools for editing of unstructured networks and interfaces for a number of SMS sub-programs.

Boundary Fitted Grid ("grill" Bottom appropriate conditions). It contains tools for editing "grids" structured and appropriate to the bottom two sub interfaces.

Cartesian Grid ("grill" Cartesian). It contains tools for editing "grids" Cartesian structured and SMS interfaces for three sub-programs.

Scatter Point. It is used for surface modeling with triangular irregular network (TINs) used for background data.

Map. Used to build conceptual models using GIS objects.

$1 D$ (one-dimensional). It contains tools for one-dimensional modeling on rivers, including an editor of crossing sections for two sub-programs and interfaces of SMS.

A window of Surface Modeling System (SMS 13.0) is related in Figure 8.

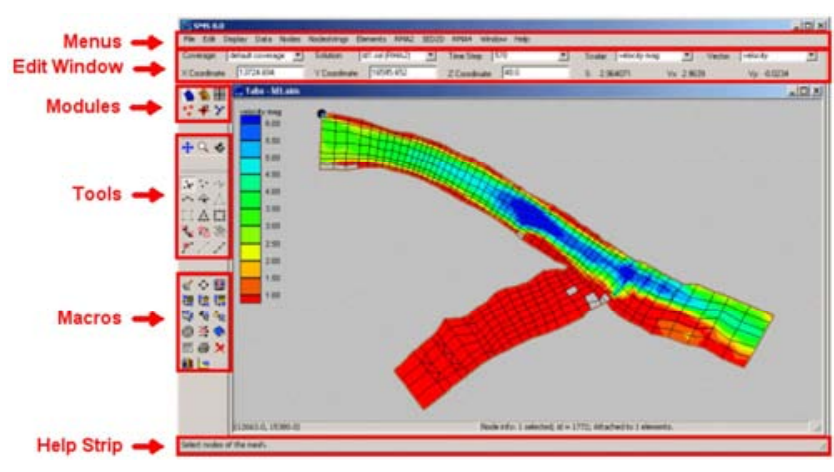

Figure 8. A window of SMS program.

For the construction of models in SMS program there are two methods: direct approach and conceptual modeling approach. In the first method, the first step is to create a mesh or a grid.

Model parameters, data from the source and bottom conditions are treated as direct networks, nodes and elements of the net. This approach is suitable only for the study of simple eutrophication models.

The most effective approach to build realistic, complex and conceptual models is a conceptual modeling. With it, we create a conceptual model using GIS features, including points, arcs and polygons (Figure 9). 


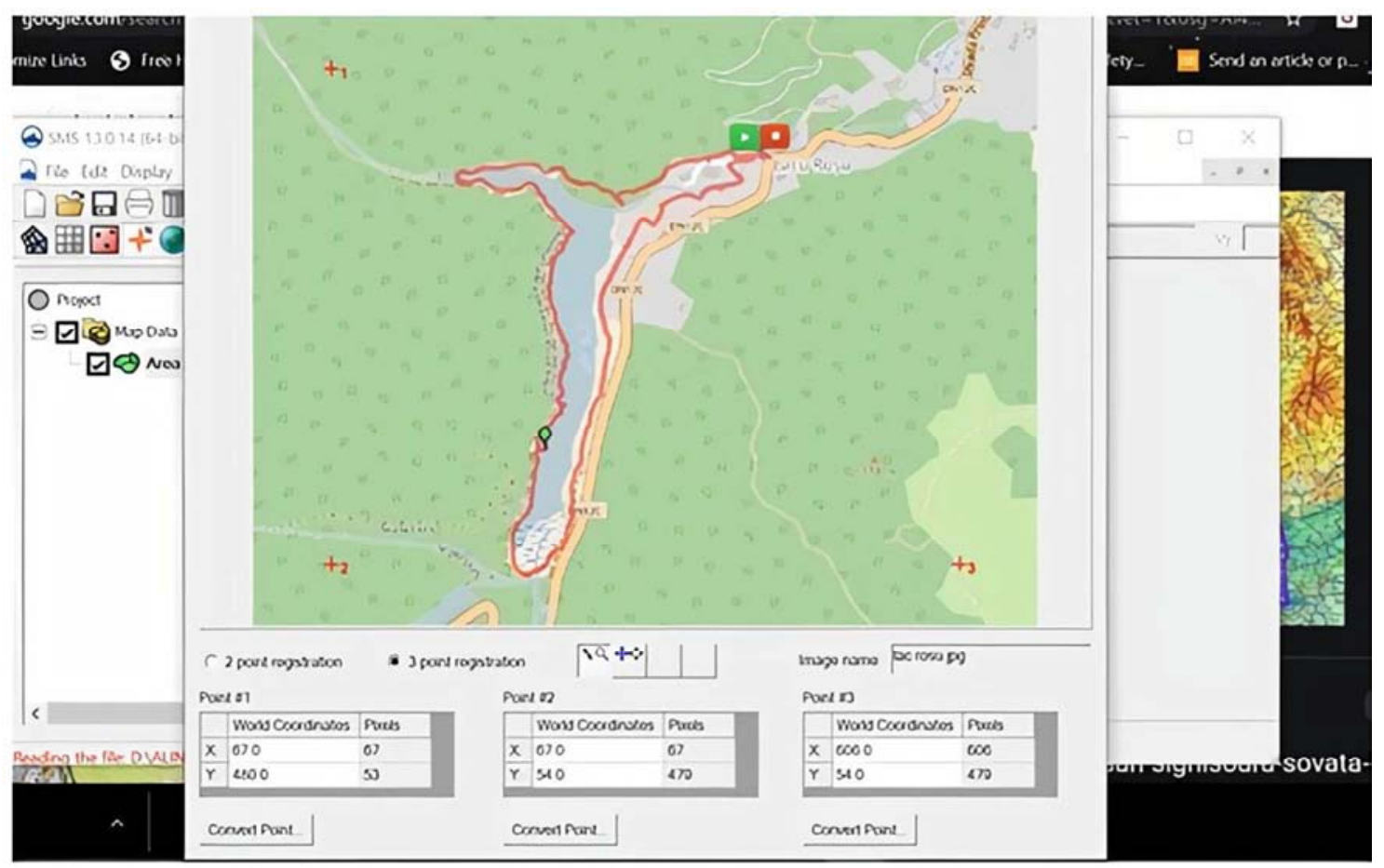

Figure 9. Conceptual model using GIS features.

We choose two models: MASH and MAP. MESH module is designed for using finite elements. A finite element mesh is defined as a network of triangulation or quadrilatere elements constructed of nodes.

That creation requires to use bathymetric, and to establish extremity for the studied area.

MAP module produces tools for defining the conditions in the study area and the characteristics of the finite element mesh with establishing those which may be created in place. Then, SMS program interpolates bathymetric and hydro-chemical, biological, bacteriological data of the network.

At building the model using SMS, the first step is importing and registering a scanned digital image or of a GIS file or even aerial photos.

For the phosphate indicator, for example, in points with a depth of $\mathrm{h}=30 \mathrm{~m}$, we obtained the correlation related in figure 10.

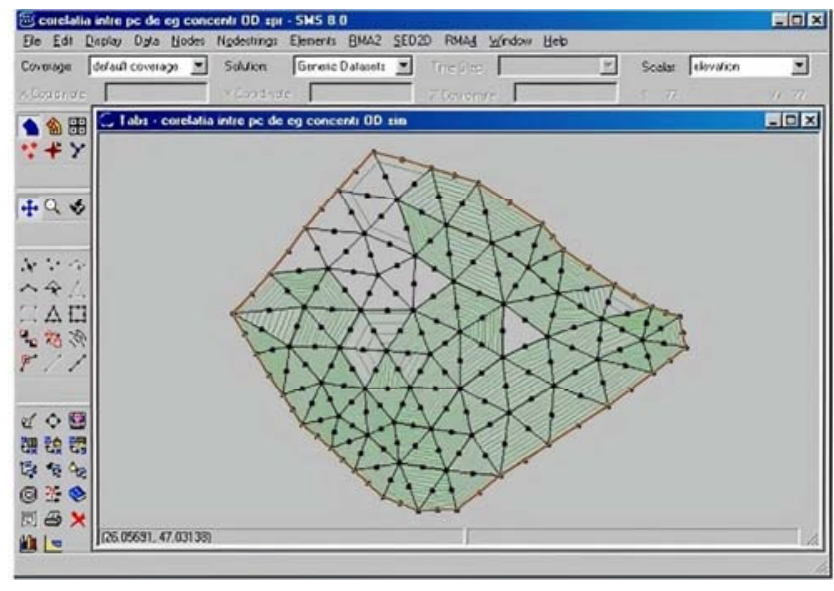

Figure 10. Polygon in MESH mode for the phosphate parameter.
From the MAP module, we selected the obtained polygon, and converted to MESH module. Here, the SMS program automatically interpolates the values entered for the boundary nodes, helped by some known values of waypoints.

With characteristic parameters entered into the program, it automatically checks them. Thus, using SMS program, we conducted a conceptual model of the variation in concentrations of the main eutrophycation's indicators: dissolved oxygen, organic matter, $\mathrm{NH}_{4}$ and total $\mathrm{P}$ in the network.

Model calibration involves changing the input parameters until the results match exactly the model of Red Lake conditions. SMS 13.0 contains a number of options to calibrate the model, among which targets specific calibration plots and statistical ones $[7,8,12,16]$.

\section{Conclusions}

Surface Modeling System helped us to obtain a conceptual model of the variation in concentrations of the main eutrophycation's process studied parameters, in the created nodes.

The results correspond to the previous land determinations.

They support both mathematical and graphical calculations and fits the lake water in terms of in the mesotrophic eutrophic category.

In the same manner, we can extend the model for any depth of the lake (10 m, $20 \mathrm{~m}$, etc.), and also for any storage lake.

Expanding research for the whole surface of the lake, possibly taking into account other water depths, we can draw conclusions about trophic lake fits, but also on water quality in the analyzed lake, depending on the parameters (data) as known to it. 
The package software we used, applied on data obtained for each year since 2012 to 2019 , verified the field data automatically, signaling errors that may occur, thereby contributing to the accuracy of final results.

A problem often overlooked consists in the real-world application of water quality models. They are a means of achieving a set of management and monitoring objectives, not an end themselves.

In many cases, it may not be necessary to use a water quality model at all, even when it is known in advance that a project will affect the water quality.

Environmental projects leaders should remember in their activities that the accuracy of model projections is severely constrained by the quality and the quantity of the available data used to calibrate, and test the models.

The hypothetical examples given above explicitly assume that these data are readily available, but this will often not be the case in practice.

The effects of eutrophication on the environment may, have deleterious consequences for the health of exposed animal and human populations, through various pathways.

Specific health risks appear when fresh water, extracted from eutrophic areas, is used for the production of drinking water. Severe impacts can also occur during animal watering in eutrophicated waters $[12,14,15]$.

People may be exposed to toxins through the consumption of contaminated drinking water, direct contact with fresh water or the inhalation of aerosols.

Toxins induce damage in animals and humans by acting at the molecular level and consequently affecting cells, tissues and organs. The nervous, digestive, respiratory and cutaneous systems may be affected. Secondary effects can be observed in numerous organs.

\section{References}

[1] Agafiței Alina, Agafiței, M., "Contributions at study of lakes eutrophycation from Moldavian Central Hill”, Simpoz. U. S. A M. V., Bucharest, F. I. F. I. M., pp. 313-318, ISBN 973-648-020-8, 17-18 May 2002.

[2] Agafiței Alina, Macoveanu M. Contributions to Control of the Eutrophycation Process for "Izvoru Muntelui" Storage Lake Water". Bul. U. T. I., tom XLVI (LI), fasc. 1-4, Hidrotechnics, March, 2006.
[3] Agafitei Alina, Comisu Oana, Agafitei M., "Eutrophication of Storage Lakes Water”, Edit. PIM, Yassy, 216 pp., 2010.

[4] Eilers, P., Peeters, J., "A model for the relationship between light intensity and the rate of photosynthesis in phytoplankton", in Ecological Modelling, no. 42, pp. 199-205, 1988.

[5] Goldsborough, L. G. \& Robinson, "G. G. C. - Pattern in wetlands. Algal Ecology. Freshwater Benthic Ecosystems", R. J. Stevenson, M. L. Bothwell \& R. L. Lowe (eds), Academic Press, San Diego, CA, p. 77-117, 1996.

[6] Henze, M. et all, "Wastewater and biomass characterization for the activated sludge model no. 2: biological phosphorus removal". Water Sci. Tech. Vol 31, no 2, 13-23, 1995.

[7] Ionescu, P., et all, ""Quality Assessment of Some Freshwater Resources Located in Bucharest and Surrounding Areas II. Water quality assessment of Arges and Dambovita rivers", in Rev. Chemical, Bucharest, vol. 70, pp. 3638-3643, 2019.

[8] Ismail, A. \& Robescu, L. D., "Assessment of the water quality of the Danube river using water quality indices technique", Environmental Engineering Management Journal, vol. 18, pp. 1727-1737, 2019.

[9] Kenney, B. C., "Dynamique du phosphore dans les systemes lacustres". Report no. 45 of INRH, study no 182, pp. 1-21, Canada, 1990.

[10] Leinster, P., "Eutrophication". Environmental Protection Agency, USA, 32 pp., 2000.

[11] Moss, B., "Shallow lakes, biomanipulation and eutrophication". Scope newsletter, vol. 29, Australia, pp. 1-44, 1998.

[12] Pricope, F., "Ecological monitoring”. Ed. Alma Mater, Bacau, 65 pp., 2018.

[13] Recht, H. L., Ghassemi, M., "Federal Water Quality Administration. Phosphate removal from wastewaters using Lanthanum precipitation”, Washington, 20242, 2007.

[14] Ryding, S. O., Rast, W., "The control of eutrophication of lakes and reservoirs". Paris, vol. I, UNESCO, 1989.

[15] Scheffer, M., Carpenter, S., Foley, J. A., Folke, C. \& Walker, B., "Catastrophic shifts in ecosystems", in Nature, vol. 413, pp. 591-96, 2001.

[16] Wild, R. et all, "Synthesis of denitrification enzymes in activated sludge: modeling with structured biomass". Water Sci. Tech. Vol. 30, no. 6, 113-122, 1994. 